\title{
Physical Activity and Fat-Related Eating Behavior Among Patients with Cholelithiasis in Erbil City: A Case-Control Study
}

\author{
Ali Taher Mohammed-Ameen; Department of Nursing, College of Nursing, Hawler Medical University, Erbil, Iraq. \\ Yousif Mohammed Younis; Department of Nursing, College of Nursing, Hawler Medical University, Erbil, Iraq.

\section{ABSTRACT}

Background and objective: The effect of physical activity and diet is an essential modifiable or environmental factor. Evidence from epidemiological studies suggests that assessing associations between diet and general health is important. The aim of the study was to assess the level of physical activity and fat-related eating behaviour of patients with cholelithiasis.

Methods: A matched case-control study was done on 100 participants; 50 were patients with gallstone disease and 50 were patients without gallstone disease. The study was conducted from December 2017 to June 2018. The constructed questionnaire used and designed based on the literature review. It consisted of four parts: demographic data, physical activity, fat-related eating behaviour, and investigations. Ultrasounds were done on all study participants to confirm whether patients had gallstone disease or not. Reliability of the questionnaire was determined through a pilot study and the validity through a panel of experts from medicine and nursing fields. Frequency, percentage, mean and standard deviation, and the chi-square test was used for analyzing data.

Results: In total, 70 female and 30 male patients were investigated. Most (52\%) were 28 to 47 years old. Most (72\%) were physically inactive. Regarding fat-related eating behaviour most (73\%) had unhealthy behavior. There was a significant association between physical activity and the risk of getting cholelithiasis. Risk of disease the development was about 2.8 times higher in patients who were physically inactive (odds ratio $=2.79,95 \% \mathrm{Cl} ; 1.1-$ 7.0) in comparison to patients were physically active. There was no significant difference between development of cholelithiasis and unhealthy fat-related eating behaviour (odds ratio $=0.886,95 \% \mathrm{Cl} ; 0.338-2.323$ ).

Conclusion: There is a significant relationship between cholelithiasis and engaging in physical activity.

Keywords: Gallstone, Diet, Activity, Case-Control Study.

\section{INTRODUCTION}

Cholelithiasis is the medical term of gallstone disease; Cholelithiasis denotes stones inside the gallbladder. Gallstone formation represents the most common abnormality of the biliary system [1]. They are divided into two major types. First pure cholesterol (10\%). Often single stone, larger than $2.5 \mathrm{~cm}$, and round in shape. Second pure pigment (bile salts $10 \%$ ). Pigment stones are black or brown in color. The most common type is mixed stone which is more than three-quarters of all type of cholelithiasis [2].The roles of physical 
activity in protecting patients to develop cholelithiasis disease are underestimated. They are thought that the mechanisms of physical activity in inhibiting the formation of cholelithiasis include facilitating weight control [3]. A recent cohort study in the United Kingdom, after 5 years of follow-up, reveals that by $70 \%$ decreased the risk of symptomatic gallstones at the maximum level of physical activity [4]. However, from several observational studies findings, independent of body weight have been varying among several studies [5]. A cohort study in the United stated of America noted that an inverse relationship between physical activity and the risk of developing cholelithiasis disease of women [6]. Furthermore, the influence of gender differences on the association between physical activity and cholelithiasis still unidentified [7].

Regarding diet as an essential modifiable factor, mounting evidence in nutritional epidemiology recommends that the way of analysis is the most realistic approach to investigating or assessing associations between diet as a general and health or disease, in place of focusing on the single dietary component [8]. A study on public health nutrition shows that a relationship between dietary patterns and the risk of formation of cholelithiasis [9].

It seems the number of patients with cholecystectomy has increased. There is a lack of published articles in Kurdistan on this subject, and epidemiological researches could substantiate the prevailing evidence and provide new valuable information. This study aimed to assess and identify physical activity and fat-related eating behavior among patients with cholelithiasis in Erbil city.

\section{METHODS}

A descriptive, matched case-control study was conducted at Hawler Teaching Rizgary
Hospitals and Kurdistan Region. The settings of the study were both inpatient and outpatient radiological and ultrasonography departments and surgical unit (male and female sides) for both case and control group. For the case group, the investigator selected those patients who had cholelithiasis and diagnosed by sonography. While for the control group, those patients without cholelithiasis in both departments which confirmed by ultrasound. UItrasound was performed by radiologists working in the radiological department.

The study occurred from December 2017 to June 2018. Selection of case and control group were according to the following inclusion and exclusion criteria: Inclusion criteria for both groups were 18 years and older, both genders, and good verbal communication. Exclusion criteria for study and control group previous cholecystectomy for gallbladder stone and positive history of cholelithiasis treated by medications.

The matching criteria were age and gender between both the study and control group. Frequency matched principles we used in this study. Direct face to face interview method was used for data collection.

The total sample size was 98 (49 cases and 49 controls). Through the GPower software V.3.1 [10], was used for sample size estimation based on proportion of exposure among case $=0.27$, proportion of exposure among control $=0.63$, Level of significance $=$ 0.05 in $95 \% \mathrm{Cl}$, Power (1- $\beta$ err probability)= 0.95 , and Allocation ratio $=1$; from the previous case-control study in Iran [11]. We took 100 patients; 50 patients f0000or the case group and 50 patients for the control group.

A questionnaire was generated by the researcher as a result of a literature review about risk factors of gallstone in the several textbooks and updated article. It was reviewed by several experts in the medical and nursing field for the validity of the 
questionnaire. The questionnaire consisted of the following part: 1) Socio-demographic data, which included age, gender, number of children, level of education, marital status, occupational status, and residential area. 2) International physical activity questionnaires (IPAQ), short form (4 generic items). The purpose of the question forms is to deliver common mechanisms that can be used to obtain internationally comparable data on health-related physical activity. It is available in public, no agreements are essentially required to practice it, and it is open access [12]. IPAQ was extensively tested for reliability and validity, which was undertaken across 12 countries [13]. Also, recently assessed by several studies in Europa and Asia [14, 15]. In addition, used in the various field and used by several authors $[16,17]$. For scoring and analysis by using an excel spreadsheet; then automatically gives the result of physical activity into three levels as inactivity, minimally active, and health-enhancing physical activity [18]. 3) Fat-related diet behavior questionnaire [19]. This questionnaire has been used in recent studies [20,21]. Individuals participated in the case group were asked to describe their fat-related eating behaviour, before the happening of cholelithiasis for symptomatic or before knowing cholelithiasis for asymptomatic. This technique was done because symptomatic cholelithiasis is the leading cause of dietary changes and modification of diet habits, not for medical purposes, but because of the occurrence of acute gastric pain, nausea, and vomiting. 4) Sonography report: all participants assessed by a trained physician specialist in radiologist. All study samples were in the fasting status at least 6 hours before doing an ultrasound. The researcher obtained an approval letter from the Ethical Committee at the College of Nursing at Hawler Medical University. Before collecting the data, the official permission was obtained from Erbil Directorate of Health, then the researcher brought it to Hawler Teaching and Rizgary Teaching hospitals. Written informed consent was received prior to each participant's participation. A pilot study was carried out from the same setting on ten patients in the case group and ten patients in the control group to determine the reliability of the questionnaire.

Data were analyzed through the application Statistical Package for Science Service (SPSS) version 25 for Windows. Descriptive Statistical analyses were used to describe the samples such as Frequency (F) and percentage (\%) also Mean and Standard deviation. Chi-square test and odds ratio were used for assessing the association between the outcome, disease, and categorical predictors. P-value $\leq 0.05$ was considered as significant.

\section{RESULTS}

Table 1 shows that 30 patients were male and 70 patients were females. In each group, 15 were males and 35 of them were females. Regarding the age group, we categorized age into six groups; the same number of participants for each age group between cases and controls (due to matched case-control). More than half $(50 \%)$ of patients were within the age group 28-47 years. In addition, the youngest age group (18-27 years) were 12 percent. While the oldest age group (68 years and older) were only 4 percent.

The current study shows that most were married $(77 \%)$, more than half $(58 \%)$ had less than 6 children, less than two-thirds (61\%) lived in the urban area, and 34\% were unable to read and write text. Most (74\%) were non-smokers, and all smokers were cigarette smokers; $69 \%$ smoked less than 20 cigarettes per day (Table 2 ). 
Table 1: Matching criteria between study and control group

\begin{tabular}{lcccc}
\hline & Matching criteria & $\mathbf{F}(\mathbf{\%})$ & Case & Control \\
& & & $\mathbf{F}(\%)$ & $\mathbf{F}(\%)$ \\
\hline Gender & Male & $30(30)$ & $15(30)$ & $15(30)$ \\
& Female & $70(70)$ & $35(70)$ & $35(70)$ \\
Age Groups & Total & $\mathbf{1 0 0 ( 1 0 0 )}$ & $\mathbf{5 0 ( 1 0 0 )}$ & $\mathbf{5 0 ( 1 0 0 )}$ \\
& $18-27$ Years & $12(12)$ & $6(12)$ & $6(12)$ \\
& $28-37$ Years old & $30(30)$ & $15(30)$ & $11(22)$ \\
& $38-47$ Years old & $22(22)$ & $11(22)$ & $8(16)$ \\
& $48-57$ Years old & $16(16)$ & $8(16)$ & $8(16)$ \\
& $58-67$ Years old & $16(16)$ & $8(16)$ & $2(4)$ \\
68 and older & $4(4)$ & $2(4)$ & $\mathbf{5 0 ( 1 0 0 )}$ \\
Total & $\mathbf{1 0 0}$ & $\mathbf{5 0 ( 1 0 0 )}$ & $\mathbf{4 2 . 5 \pm 1 3 . 2}$ \\
\hline
\end{tabular}

Table 2: Sociodemographic data of the study sample

\begin{tabular}{|c|c|c|c|c|}
\hline \multicolumn{2}{|c|}{ Sociodemographic data } & \multirow{2}{*}{$\frac{\mathbf{F}(\%)}{13(13)}$} & \multirow{2}{*}{$\begin{array}{r}\text { Case F (\%) } \\
5(10)\end{array}$} & \multirow{2}{*}{$\begin{array}{c}\text { Control F (\%) } \\
8(16)\end{array}$} \\
\hline Marital Status & Single & & & \\
\hline & Married & $77(77)$ & $38(76)$ & $39(78)$ \\
\hline & Widowed & $8(8)$ & $5(10)$ & $3(6)$ \\
\hline & Divorced & $2(2)$ & $2(4)$ & -- \\
\hline Number(s) of & 0 to 5 children & $51(58)$ & $28(62)$ & $23(55)$ \\
\hline \multirow[t]{2}{*}{ children } & 6 to 10 children & $30(35)$ & $13(29)$ & $17(40)$ \\
\hline & 11 to 15 children & $6(7)$ & $4(9)$ & $2(5)$ \\
\hline \multirow[t]{3}{*}{ Residency } & Urban & $61(61)$ & $28(56)$ & $33(66)$ \\
\hline & Rural & $1(1)$ & $1(2)$ & -- \\
\hline & Sub-Urban & $38(38)$ & $21(42)$ & $17(34)$ \\
\hline Educational lev- & Illiterate & $34(34)$ & $18(36)$ & $16(32)$ \\
\hline \multirow[t]{7}{*}{ el } & Able to read \& write & $14(14)$ & $6(12)$ & $8(16)$ \\
\hline & Primary school & $22(22)$ & $13(4)$ & $9(18)$ \\
\hline & Secondary school & $12(12)$ & $4(4)$ & $8(16)$ \\
\hline & High school & $6(6)$ & $2(4)$ & $4(8)$ \\
\hline & Diploma & $6(6)$ & $2(4)$ & $4(8)$ \\
\hline & Bachelor degree & $5(5)$ & $4(8)$ & $1(2)$ \\
\hline & Master degree & $1(1)$ & $1(2)$ & -- \\
\hline Occupation & Housewife & $63(63)$ & $32(64)$ & $31(62)$ \\
\hline \multirow[t]{4}{*}{ state } & Retired & $2(2)$ & $2(4)$ & -- \\
\hline & Student & $5(5)$ & $1(2)$ & $4(8)$ \\
\hline & Work in Public sector & $16(16)$ & $8(16)$ & $8(16)$ \\
\hline & Work in private sector & $14(14)$ & $7(14)$ & $7(14)$ \\
\hline Habit of smok- & Non-smoker & $74(74)$ & $35(70)$ & $39(78)$ \\
\hline \multirow[t]{2}{*}{ ing } & Ex-Smoker & $5(5)$ & $3(6)$ & $2(4)$ \\
\hline & Smoker & $21(21)$ & $12(24)$ & $9(18)$ \\
\hline Current alcohol & Yes & $0(0)$ & $0(0)$ & $0(0)$ \\
\hline drinker & No & $100(100)$ & $50(100)$ & $50(100)$ \\
\hline
\end{tabular}


Table 3 shows that $72 \%$ of the participants were physically inactive. Among cases, $82 \%$ of them were inactive, while $62 \%$ of controls were inactive. There were more minimally active participants among controls (38\%), compared to cases (18\%). There was a statistically significant association between physical activity and cholelithiasis $(p=0.044)$.
Regarding fat-related eating behavior (Table 4), the highest percentage $(60 \%)$ of patients were unhealthy and $21 \%$ had good fat-related eating behaviour. Roughly double $(24 \%)$ the cases had poor diet behaviour when compared to controls (14\%). There was no significant association between fat behaviour and cholelithiasis.

Table 3: Physical activity and its association with cholelithiasis

\begin{tabular}{lcccc}
\hline \multicolumn{1}{c}{ Physical activity } & Total & Case & Control & P-value* \\
& F (\%) & F (\%) & F (\%) & \\
\hline Inactive & $72(72)$ & $41(82)$ & $31(62)$ & $19(38)$ \\
Minimally Active & $28(28)$ & $9(18)$ & -- & $\mathbf{S}$ \\
HEPA active & -- & -- & $\mathbf{5 0 ( 1 0 0 )}$ & \\
\hline
\end{tabular}

HEPA= Health Enhancement Physical Activity; S=significant; ${ }^{*}=$ Chi-Square Test;

Table 4: Fat-related eating behavior and its association with cholelithiasis

\begin{tabular}{|c|c|c|c|c|}
\hline Fat-related eating behavior categories & $\begin{array}{l}\text { Total } \\
\text { F (\%) }\end{array}$ & Case $\mathbf{F}(\%)$ & $\begin{array}{c}\text { Control F } \\
(\%)\end{array}$ & P-value* \\
\hline Best fat-related eating behavior & -- & -- & -- & \multirow{5}{*}{$\begin{array}{l}.066 \\
\text { NS }\end{array}$} \\
\hline Good fat-related eating behavior & $21(21)$ & $11(22)$ & $10(20)$ & \\
\hline Bad fat-related eating behavior & $72(72)$ & $32(64)$ & $28(56)$ & \\
\hline Worst fat-related eating behavior & $28(28)$ & $7(14)$ & $12(24)$ & \\
\hline Total & $100(100)$ & $50(100)$ & $50(100)$ & \\
\hline
\end{tabular}

NS=non-significant; * ${ }^{*}$ Chi-Square Test

\section{DISCUSSION}

This study aimed to assess the effect of physical activity and eating fatty food on the formation of gallbladder stones in order to understand the association between these two lifestyle factors with cholelithiasis. In this study, physical activity appears to be associated with cholelithiasis. In China, several authors found that physical activity may reduce the risk of cholelithiasis formation [22].

Likewise, several recent studies described the protective effect of physical activity on gallstones [23, 24]. While some earlier studies have not given a decision about the effect of activity on the disease [25, 26]. A recent study reveals that there is an association for the male gender but not for female gender [27]. One suggested a mechanism behind the protective effect of physical activity is a reduced colonic transit time associated with increased gallbladder motility and a reduced intestinal bile salt dihydroxylation [28]. Generally, these findings topic to likely usefulness of lifestyle modification as effective actions for the prevention of cholelithiasis.

Findings for physical activity are inconsistent with the previous studies done in 
United Kingdom; which found that there was a statistically non-significant association between physical activity and cholelithiasis [29]. In Mexico, a study done about women found that no differences in the frequencies of persons that performed some form of moderate physical exercise with the women who have a sedentary lifestyle and cholelithiasis formation [30].

In current study showed that there is no relation between fat-related eating behaviour and cholelithiasis. The role of lipids in the cholesterol gallstones formation of currently remains uncertain [31]. Fatty acid classes naturally occurring such as saturated, monounsaturated and polyunsaturated; none of the fatty acids were associated with gallstone disease in men and women [29]. Another case-control study showed that non-association in used of more than $600 \mathrm{ml}$ of oil among men and women with cholelithiasis and without cholelithiasis participants [32].

Inconsistency with other case-control studies found that there is an association between the consumption of total fat in the group of cases was significantly higher as compared to controls; the study sample was including women participant only [30, 33]. Similarly, earlier French research presented a positive link between gallstone disease and total fat intake [34]. In prospective follow-up studies; a higher intake of saturated and trans-fatty acids were associated with a heightened risk of gallstones [35, 36]. Cuevas et, al in Chile found that a higher intake of mono- and polyunsaturated fatty acids, which were correlated with reduced risk of cholelithiasis [37]. In an epidemiological study detected a negative association between cholesterol consumption and gallstone disease [38].

\section{CONCLUSION}

This study concluded that cholelithiasis more frequently in the female, young adult, married, less than 5 children, illiterate, housewife, non-smoker, and overweight to Obese class I. There was a significant association between physical activity and having cholelithiasis, but not significant association between eating fatty food with cholelithiasis.

\section{CONFLICT OF INTEREST}

There is no actual or potential conflict of interest in relation to this study.

\section{FINANCIAL SUPPORT}

There is no financial support for this study.

\section{REFERENCES}

[1] Timby BK, Smith NE. Introductory MedicalSurgical Nursing. 10th ed. Philadelphia: Lippincott William \& Wilkin; 2010. p.720.

[2] McLatchie G, Borley N, Chikwe J, (ed.). Oxford Handbook of Clinical Surgery. 4th ed. United Kingdom: Oxford University Press; 2013.

[3] Dietz WH, Baur LA, Hall K, Puhl RM, Taveras EM, Uauy R, et al. Management of obesity: improvement of health-care training and systems for prevention and care. The Lancet. 2015;385(9986):2521-2533, https:// doi.org/10.1016/s0140-6736(14)61748-7.

[4] Banim PJ, Luben RN, Wareham NJ, Sharp SJ, Khaw K-T, Hart AR. Physical activity reduces the risk of symptomatic gallstones: a prospective cohort study. European journal of gastroenterology \& hepatology. 2010;22 (8):983-988,

[5] Misciagna G, Centonze S, Leoci C, Guerra V, Cisternino AM, Ceo $R$, et al. Diet, physical activity, and gallstones-a population-based, case-control study in southern Italy. The American Journal of Clinical Nutrition. 1999;69(1):120-126,https:// doi.org/10.1093/ajcn/69.1.120.

[6] Storti KL, Brach JS, FitzGerald SJ, Zmuda JM, Cauley JA, Kriska AM. Physical activity and decreased risk of clinical gallstone disease among post-menopausal women. Preventive medicine.2005;41(3-4):772-777, https:// doi.org/10.1016/j.ypmed.2005.04.002. 
[7] Lindseth G, Bird-Baker MY. Risk factors for cholelithiasis in pregnancy. Research in nursing \& health. 2004;27(6):382-391, https:// doi.org/10.1002/nur.20041.

[8] Hu FB. Dietary pattern analysis: a new direction in nutritional epidemiology. Current opinion in lipidology. 2002;13(1):3-9, https:// doi.org/10.1097/00041433-20020200000002.

[9] Tseng M, Everhart JE, Sandler RS. Dietary intake and gallbladder disease: a review. Public health nutrition. 1999;2(2):161172,https://doi.org/10.1017/ s136898009900021x.

[10] Faul F, Erdfelder E, Buchner A, Lang A-G. Statistical power analyses using G*Power 3.1: Tests for correlation and regression analyses. Behavior Research Methods. 2009;41:11491160,

[11] Jessri M, Rashidkhani B. Dietary patterns and risk of gallbladder disease: A hospital-based case-control study in adult women. Journal of Health, Population, and Nutrition. 2015;33 (1):39,

[12] IPAQ. International Physical Activity Questionnaire Online: IPAQ; 2002 [updated 12 Jan 2012; cited 2017 November]. Available from: https://sites.google.com/site/theipaq/.

[13] Dai S. Validity of the international physical activity questionnaire short form (IPAQ-SF) in adults: a systematic review: The University of Hong Kong; 2015, Thesis, Retrieved from: https://doi.org/10.5353/th_b5662548.

[14] Macfarlane DJ, Lee CC, Ho EY, Chan KL, Chan DT. Reliability and validity of the Chinese version of IPAQ (short, last 7 days). Journal of Science and Medicine in Sport. 2007;10 (1):45-51, https://doi.org/10.1016/ j.jsams.2006.05.003.

[15] Boon RM, Hamlin MJ, Steel GD, Ross JJ. Validation of the New Zealand physical activity questionnaire (NZPAQ-LF) and the international physical activity questionnaire (IPAQLF) with accelerometry. British Journal of Sports Medicine. 2010;44(10):741-746, https://doi.org/10.1136/bjsm.2008.052167.

[16] Duncan MJ, Arbour-Nicitopoulos K, Subramanieapillai M, Remington G, Faulkner G. Revisiting the International Physical Activity Questionnaire (IPAQ): Assessing physical activity among individuals with schizophrenia. Schizophrenia research. 2017;179:2-7, https:// doi.org/10.1016/j.schres.2016.09.010.
[17] Hirvensalo $M$, Magnussen CG, Yang X, Telama $R$, Heinonen I, Hutri-Kähönen $N$, et al. Convergent Validity of a Physical Activity Questionnaire against Objectively Measured Physical Activity in Adults: The Cardiovascular Risk in Young Finns Study. Advances in Physical Education. 2017;7(04):457-472, https://doi.org/10.4236/ape.2017.74038.

[18] Blasio AD, Donato FD, Mazzocco C. IPAQ AUTOMATIC REPORT - English version online: IPAQ; 2016 [updated 30 Jul 2016; cited 2017 November]. Available from: https://docs.google.com/viewer? $\mathrm{a}=\mathrm{v}$ \&pid=sites\&srcid=ZGVmYXVsdGRvbWFp bnx0aGVpcGFxfGd4OjUxNjA1MzU5ZDI3NjVi NmQ.

[19] Shannon J, Kristal AR, Curry SJ, Beresford S. Application of a behavioral approach to measuring dietary change: the fat-and fiberrelated diet behavior questionnaire. Cancer Epidemiology and Prevention Biomarkers. 1997;6(5):355-361, Retrieved from: http:// www.scopus.com/inward/record.url? scp=0030987393\& partnerID=8YFLogxK.

[20] Hendrychova T, Vytrisalova M, Vlcek J, Smahelova A, Kubena AA. An analysis of fatrelated and fiber-related behavior in men and women with type 2 diabetes mellitus: key findings for clinical practice. Patient preference and adherence. 2013;7:877-884, https://doi.org/10.2147/ppa.s47497.

[21] Hendrychova T, Vytrisalova M, Alwarafi A, Tebbens JD, Vankatova $\mathrm{H}$, Leal $\mathrm{S}$, et al. Fatand fiber-related diet behavior among type 2 diabetes patients from distinct regions. Patient preference and adherence. 2015;9:319-325, https://doi.org/10.2147/ ppa.s71373.

[22] Hou L, Shu X-O, Gao Y-T, Ji B-T, Weiss JM, Yang $G$, et al. Anthropometric measurements, physical activity, and the risk of symptomatic gallstone disease in Chinese women. Annals of Epidemiology. 2009;19 (5):344-350, https://doi.org/10.1016/ j.annepidem.2008.12.002.

[23] De Oliveira EP, Burini RC. The impact of physical exercise on the gastrointestinal tract. Current Opinion in Clinical Nutrition \& Metabolic Care. 2009;12(5):533-538, https://doi.org/10.1097/ mco.0b013e32832e6776. 
[24] AV A, KG K. Diabetes Mellitus and Other Lifestyle Risk Factors for Cholelithiasis: A Case Control Study. International Journal of Preventive and Therapeutic Medicine. 2015;3(1), Retrived from: http://ijptm.com/index.php/ ijptm/article/view/270.

[25] Jørgensen T, Kay L, Schultz-Larsen K. The epidemiology of gallstones in a 70-year-old Danish population. Scandinavian Journal of Gastroenterology. 1990;25(4):335-340, https:// doi.org/10.3109/00365529009095495.

[26] Basso L, McCollum P, Darling M, Tocchi W, Tanner W. A descriptive study of pregnant women with gallstones. Relation to dietary and social habits, education, physical activity, height, and weight. European Journal of Epidemiology. 1992;8(5):629-633, https:// doi.org/10.1007/bf00145375.

[27] Liu T, Wang W, Ji Y, Wang Y, Liu X, Cao L, et al. Association between different combination of measures for obesity and new-onset gallstone disease. Plos one. 2018;13 (5):e0196457, https://doi.org/10.1371/ journal.pone.0196457.

[28] Lammert F, Sauerbruch T. Mechanisms of disease: the genetic epidemiology of gallbladder stones. Nature Reviews Gastroenterology and Hepatology. 2005;2(9):423, https://doi.org/10.1038/ncpgasthep0257.

[29] Banim PJ. Aetiological and clinical aspects of symptomatic gallstone disease and pancreatic cancer. Norwich: University of East Anglia; 2011, Thesis, Retrieved from: https:// ueaeprints.uea.ac.uk/id/eprint/49763.

[30] Ruvalcaba CB, Hita MG, Sanchez-Enriquez S. Diet and Nutritional Factors Related to Symptomatic Gallstone Disease in Women. Journal of Clinical Case Rep. 2014;4(12), https://doi.org/10.4172/2165-

7920.1000458.

[31] Stokes CS, Krawczyk M, Lammert F. Gallstones: environment, lifestyle and genes. Digestive Diseases. 2011;29(2):191-201, https://doi.org/10.1159/000323885.

[32] Jayanthi V, Anand L, Ashok L, Srinivasan V. Dietary factors in pathogenesis of gallstone disease in southern India - a hospital-based case-control study. Indian journal of gastroenterology. 2005;24(3):97-99, Retrieved from: https://www.ncbi.nlm.nih.gov/ pubmed/16041099.
[33] Pixley F, Mann J. Dietary factors in the aetiology of gall stones: a case control study. Gutbmj. 1988;29(11):1511-1515, https:// doi.org/10.1136/gut.29.11.1511.

[34] Caroli-Bosc F-X, Deveau C, Peten EP, Delabre $B$, Zanaldi $H$, Hebuterne $X$, et al. Cholelithiasis and dietary risk factors (an epidemiologic investigation in Vidauban, Southeast France). Digestive diseases and sciences. 1998;43(9):2131-2137, https:// doi.org/10.1023/A:1018879819301.

[35] Tsai C-J, Leitzmann MF, Willett WC, Giovannucci EL. Long-term intake of trans-fatty acids and risk of gallstone disease in men. Archives of Internal Medicine. 2005;165 (9):1011-1015, https://doi.org/10.1001/ archinte.165.9.1011.

[36] Tsai C-J, Leitzmann MF, Willett WC, Giovannucci EL. Long-chain saturated fatty acids consumption and risk of gallstone disease among men. Annals of Surgery. 2008;247 (1):95-103, https://doi.org/10.1097/ sla.0b013e31815792c2.

[37] Cuevas A, Miquel JF, Reyes MS, Zanlungo S, Nervi F. Diet as a risk factor for cholesterol gallstone disease. Journal of the American College of Nutrition. 2004;23(3):187-196, http:// dx.doi.org/10.1080/07315724.2004.107193 60.

[38] Marchesini G, Forlani G. NASH: from liver diseases to metabolic disorders and back to clinical hepatology. Hepatology. 2002;35 (2):497-499, https://doi.org/10.1053/ jhep.2002.31551. 